\title{
Cross sectional echocardiographic assessment of great artery diameters in infants and children
}

\author{
FUKIKO ICHIDA, ANDRÉ AUBERT, BOUDEWIJN DENEF, MONIQUE \\ DUMOULIN, LUCAS G VAN DER HAUWAERT \\ From the Section of Paediatric Cardiology, Department of Paediatrics, Gasthuisberg University Hospital, \\ Leuven, Belgium
}

SUMMARY The pulmonary trunk and aortic root were measured on cross sectional echocardiograms in 173 normal subjects aged from one day to 15 years. Fifteen neonates were reexamined 3-6 days later. The great vessels were visualised in the parasternal long axis and short axis views. All measurements were made in end diastole and end systole by the leading edge method. The internal diameter (inner surface to inner surface) of the pulmonary trunk was also measured. The diameters of the great vessels correlated best with the square root of body surface area. Individual variability in cardiac growth gave a wide scatter of normal values. This was controlled for by calculating the ratio of the pulmonary trunk to aortic root for each subject. This ratio showed little individual variability and, except for the neonatal period, was remarkably constant throughout infancy and childhood $(1.06(0.06))$. In the first 24 hours of life the ratio of the pulmonary trunk to the aortic root was significantly larger $(1 \cdot 29(0 \cdot 12))$ but within one week it decreased to the "normal" ratio found in the older age groups.

These normal data should be useful in assessing patients with congenital heart disease, particularly those in whom pulmonary blood flow is abnormal.

Congenital heart disease is often associated with increased or decreased pulmonary artery blood flow or blood pressure. The relation between pulmonary artery diameter and pulmonary flow or pressure has been evaluated in pathological, ${ }^{12}$ angiocardiographic $^{34}$ and, more recently, echocardiographic studies. ${ }^{56}$ In children with a left to right shunt excellent correlations have been found between shunt size and pulmonary artery diameter on cross sectional echocardiograms, particularly when pulmonary artery size was related to the diameter of the aortic root. ${ }^{57}$ In patients with decreased pulmonary flow, as in tetralogy of Fallot, the diameter of the pulmonary artery has been used as an important criterion for selecting patients for total correction. 8

Few cross sectional echocardiographic data are available on the normal values of pulmonary trunk

Requests for reprints to Dr Lucas G Van der Hauwaert, Section of Paediatric Cardiology, Department of Paediatrics, Gasthuisberg University Hospital, 3000 Leuven, Belgium.

Accepted for publication 29 June 1987 and aortic root size in children. ${ }^{5-7}$ Some results are controversial because of the echocardiographic view and measuring techniques that were chosen. To provide normal values through a wide range of ages and body surface areas, we measured the diameter of the great vessels in a large group of neonates, infants, and children and we analysed some variables which might influence these measurements. We also did repeat studies on a subgroup of 15 neonates to determine the changes that occurred in the first week of life.

\section{Patients and methods}

We studied 173 children ( 97 boys and 76 girls) in whom good quality cross sectional echocardiograms were obtained. Physical examination, an electrocardiogram, and the echocardiogram itself helped to exclude cardiac disease. Patients with respiratory disorders, severe anaemia, a febrile illness, or a disease known to alter cardiac function were excluded. Two groups of subjects were evaluated.

Group 1 consisted of 20 normal neonates from the Maternity Hospital. Mean (1 SD) gestational age 


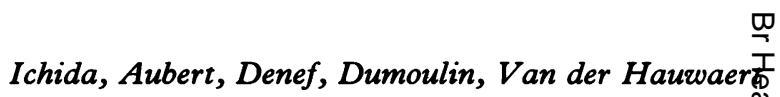

was $39.5(0.9)$ weeks and mean weight was $3.41(0.30) \mathrm{kg}$. This group was further subdivided according to age. Subgroup $1 \mathrm{~A}$ was 10 neonates examined within 12 hours of birth and subgroup $1 B$ 10 neonates examined between 12 and 24 hours of life. Fifteen of these 20 infants were restudied 3-6 days after the initial examination.

Group 2 consisted of 153 infants and children, aged one week to 15 years (mean 4.4 years). They were taken at random from the outpatient or inpatient services of the hospital or were the children of employees of the hospital or medical school. In selecting subjects we tried to obtain a more or less equal distribution across the age groups and range of body surface area. Weight and height were reported at the time of echocardiography. The body surface area was calculated by the Boothby and Sandiford modification of the Dubois nomogram. ${ }^{9}$

\section{ECHOCARDIOGRAPHIC STUDIES}

Cross sectional echocardiographic examinations were performed with an ATL/ADR mechanical sector scanner with 3.5 or $5 \mathrm{MHz}$ focused transducers. The instrument had built-in movable electronic callipers which automatically calculated the distance between two points. All diameters were directly measured on the video screen of the scanner. The subjects were examined in the supine or left lateral decubitus position. The pulmonary artery was imaged in the parasternal right ventricular long axis view. This section allows good visualisation of the entire right ventricular outflow region, the pulmonary valve, and the pulmonary trunk. The diameter of the pulmonary trunk was measured at the pulmonary valve level (fig 1a). The aortic root diameter was imaged in the parasternal left ventricular long axis view and its diameter was measured distal to the sinuses of Valsalva (fig $1 \mathrm{~b}$ ). In addition, both great arteries were imaged simultaneously in the parasternal short axis view. In this instance the diameters of the pulmonary trunk and aortic root were measured at valve level.

Measurements were made by the leading edge method. This technique could not always be applied reliably to the pulmonary artery imaged in the parasternal short axis view. For comparison we used both methods (leading edge and inner to inner surface) to measure the pulmonary trunk in the parasternal long axis view. All measurements were obtained in both end diastole (at the onset of QRS) and end systole (at the onset of the $T$ wave). We took the mean value of three measurements. We also calculated the ratio of the pulmonary trunk to the aortic root in end systole and end diastole.

STATISTICAL ANALYSIS

We used a regression mode to express each echo measurement as a function of body surface area. In preliminary evaluation the echo measurements were analysed as linear, logarithmic, square root, an cube root functions of body surface area. The funes tion that had the smallest residual sum of squares and the highest correlation coefficient was used in the final regression equation. The pulmonary trun to aortic root ratio was determined from the paraj sternal long axis and short axis views and analysed as a linear function of the body surface area (table $1 \not$
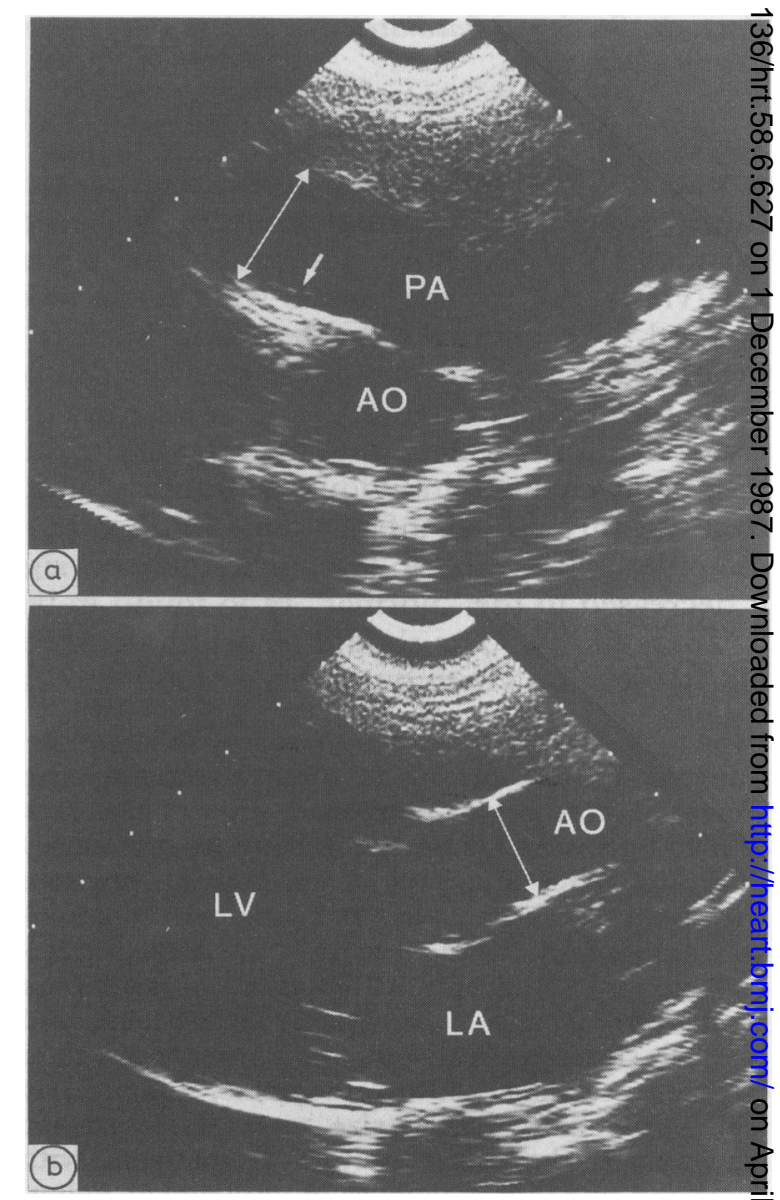

Fig 1 Echocardiographic views used for measuring the diameters of the great arteries. (a) The pulmonary trunk wass visualised in the parasternal long axis view of the right ventricular outflow tract. Measurements were made at the pulmonary valve level in end systole. One of the opened pulmonary valve leaflets is visible (arrow head). (b) The 0 aortic root was visualised in the parasternal left ventricular $\stackrel{\complement}{\Phi}$ long axis view. Its diameter was measured distal to the sinus of Valsalva, where the aorta assumes a more cylindrical shape. A minimum gain was used to obtain clear and thin echo lines. $A O$, aortic root; $P A$, pulmonary trunk; $L A$, left atrium; $L V$, left ventricle. 
Table 1 Regression equations relating echocardiographic diameters of the great arteries to body surface area in 153 infants and children (group 2)

\begin{tabular}{|c|c|c|c|c|c|}
\hline View & Variable & Regression equation & $r$ & RSS & $S E E$ \\
\hline LAX & $\begin{array}{l}\text { PA } \\
\text { Ao } \\
\text { PA:Ao }\end{array}$ & $\begin{array}{l}0.031+2.258(\mathrm{BSA}) 1 / 2 \\
0.084+1.944(\mathrm{BSA}) 1 / 2 \\
1.062+0.025(\mathrm{BSA})\end{array}$ & $\begin{array}{l}0.96 \\
0.96 \\
0.07\end{array}$ & $\begin{array}{l}3.38 \\
2.76 \\
1.02\end{array}$ & $\begin{array}{l}0.05 \\
0.04 \\
0.02\end{array}$ \\
\hline SAX & $\begin{array}{l}\text { PA } \\
\text { Ao } \\
\text { PA:Ao }\end{array}$ & $\begin{array}{l}0.108+1.969(\mathrm{BSA}) 1 / 2 \\
0.153+1.958(\mathrm{BSA}) 1 / 2 \\
0.967+0.013(\mathrm{BSA})\end{array}$ & $\begin{array}{l}0.96 \\
0.95 \\
0.04\end{array}$ & $\begin{array}{l}2.97 \\
3.31 \\
0.88\end{array}$ & $\begin{array}{l}0.04 \\
0.05 \\
0.02\end{array}$ \\
\hline
\end{tabular}

PA, pulmonary artery trunk; Ao, aortic root; LAX, parasternal long axis; SAX, parasternal short axis; $r$, correlation coefficient; RSS, residual sum of squares; BSA, body surface area; SEE, standard error of the estimate. All measurements were made in end systole by the leading edge method.

The $95 \%$ confidence interval was determined according to the following equation ${ }^{10} 11$ :

$$
y_{c} \pm[2 F(0.95,2, N-2)]^{1 / 2} s(y)\left[1+1 / N+\frac{\sum\left(x_{p}-\bar{x}\right)^{2}}{\sum\left(x_{i}-\bar{x}\right)^{2}}\right]^{1 / 2}
$$

In this equation the variables are $y_{c}=$ calculated values corresponding to each $x_{p} ; \overline{\mathbf{x}}=$ mean value; $x_{i}$ $=x$ coordinates; $N=$ number of points; $F$ value: first number $=$ level of confidence desired, second $=$ the number of variables estimated, third $=$ the number of degrees of freedom for error; $s(y)=$ square root of the residual mean squares.

\section{Results}

All echocardiographic measurements were expressed as four functions of body surface area. In infants and children (group 2) the great vessel diameters were best fitted to the square root function of body surface area. Figure 2 shows the mean values and $95 \%$ prediction intervals. Table 1 lists the regression functions for these measurements and body surface area. The correlation coefficients were very high $(r \geqslant 0.95)$ and they were similar for measurements in the long axis and short axis parasternal views.
The pulmonary trunk to aortic root ratios, determined in the long axis and short axis views, were independent of body surface area (table 1) and the regression equation demonstrated a nearly straight horizontal line (fig 2c).

Neonates (group 1) differed from the main study population (group 2) in several respects (table 2). The pulmonary trunk was relatively large in the first 12 hours of life. Slightly but significantly smaller diameters were found in the groups that were 12-24 hours, 3-6 days, and 1-3 weeks old. In the 3-6 month age group the dimension of the pulmonary trunk was again equal to that at birth and from three months onwards there was a steady increase in pulmonary trunk size, related to age and body surface area (fig 3). In contrast, the aortic root dimension increased gradually with age from birth onwards. This difference in growth pattern was also expressed by the pulmonary trunk to aortic root ratio. In group 1A (age $\leqslant 12$ hours) the pulmonary trunk to aortic root ratio was $1.29(0 \cdot 12)$. This value was significantly larger $(p<0.005)$ than in neonates aged 12-24 hours, in whom the ratio of the pulmonary trunk to the aortic root was $1 \cdot 12(0 \cdot 10)$. In neonates aged 1-3 weeks the pulmonary trunk to aortic root ratio was $1.08(0.05)$, which was not significantly different from the mean value in older

able 2 Echocardiographic measurements (mean $(S D)$ ) of the diameter (cm) of the great arteries in neonates, infants, and children

\begin{tabular}{|c|c|c|c|c|c|c|c|c|c|}
\hline $\begin{array}{l}\text { fe } \\
\text { eight }(\mathrm{kg}) \\
\text { iA }\left(\mathrm{m}^{2}\right)\end{array}$ & $\begin{array}{l}\leqslant 12 \mathrm{~h} \\
10 \\
3 \cdot 40(0 \cdot 27) \\
0 \cdot 21(0 \cdot 01)\end{array}$ & $\begin{array}{l}12-24 \mathrm{~h} \\
10 \\
3.42(0.33) \\
0.21(0.01)\end{array}$ & $\begin{array}{l}3-6 \text { day } \\
15^{\star} \\
3 \cdot 40(0 \cdot 29) \\
0 \cdot 21(0 \cdot 01)\end{array}$ & $\begin{array}{l}\text { 1-4 wk } \\
8 \\
3.32(0.40) \\
0.21(0.01)\end{array}$ & $\begin{array}{l}\text { data } \\
1-3 \text { mnth } \\
21 \\
4.92(0.66) \\
0.26(0.02)\end{array}$ & $\begin{array}{l}3-6 \text { mnth } \\
17 \\
5.62(1.08) \\
0.29(0.04)\end{array}$ & $\begin{array}{l}6-12 \text { mnth } \\
12 \\
7.67(0.79) \\
0.37(0.03)\end{array}$ & $\begin{array}{l}1 w k-15 y r \\
153\end{array}$ & $\begin{array}{l}4 \mathrm{~h}-15 \mathrm{yr} \\
173\end{array}$ \\
\hline $\begin{array}{l}1 \\
\text { 1:Ao }\end{array}$ & $\begin{array}{l}1.15(0.09) \\
0.89(0.09) \\
1.29(0.12)\end{array}$ & $\begin{array}{l}1.02(0.05) \\
0.92(0.09) \\
1.12(0.10)\end{array}$ & $\begin{array}{l}1.01(0.09) \\
0.93(0.07) \\
1.09(0.08)\end{array}$ & $\begin{array}{c}\text { Paraste } \\
1.05(0.05) \\
0.98(0.07) \\
1.08(0.05)\end{array}$ & $\begin{array}{l}\text { l long axis } \\
1.09(0.11) \\
1.04(0.12) \\
1.06(0.09)\end{array}$ & $\begin{array}{l}1.19(0.11) \\
1.12(0.13) \\
1.07(0.08)\end{array}$ & $\begin{array}{l}1.41(0.14) \\
1.34(0.13) \\
1.05(0.06)\end{array}$ & $1.05(0.06)$ & $1.09(0.09)$ \\
\hline $\begin{array}{l}1 \\
\text { 1:Ao }\end{array}$ & $\begin{array}{l}1.05(0.08) \\
0.94(0.12) \\
1.13(0.13)\end{array}$ & $\begin{array}{l}0.98(0.07) \\
0.96(0.07) \\
1.02(0.10)\end{array}$ & $\begin{array}{l}0.96(0.07) \\
0.98(0.10) \\
0.99(0.11)\end{array}$ & $\begin{array}{c}\text { Paraster } \\
1.03(0.08) \\
0.99(0.08) \\
1.04(0.10)\end{array}$ & $\begin{array}{l}\text { l short axis } \\
1.08(0.10) \\
1.12(0.11) \\
0.97(0.09)\end{array}$ & $\begin{array}{l}1.15(0.12) \\
1.2(0.1) \\
0.96(0.09)\end{array}$ & $\begin{array}{l}1.33(0.11) \\
1.39(0.13) \\
0.96(0.06)\end{array}$ & $0.96(0.06)$ & $0.99(0.09)$ \\
\hline
\end{tabular}

These 15 subjects belong to the group of 20 neonates who were examined within 24 hours after birth. They were restudied 3-6 days after the initial amination.

e footnote to table 1 for abbreviations. 

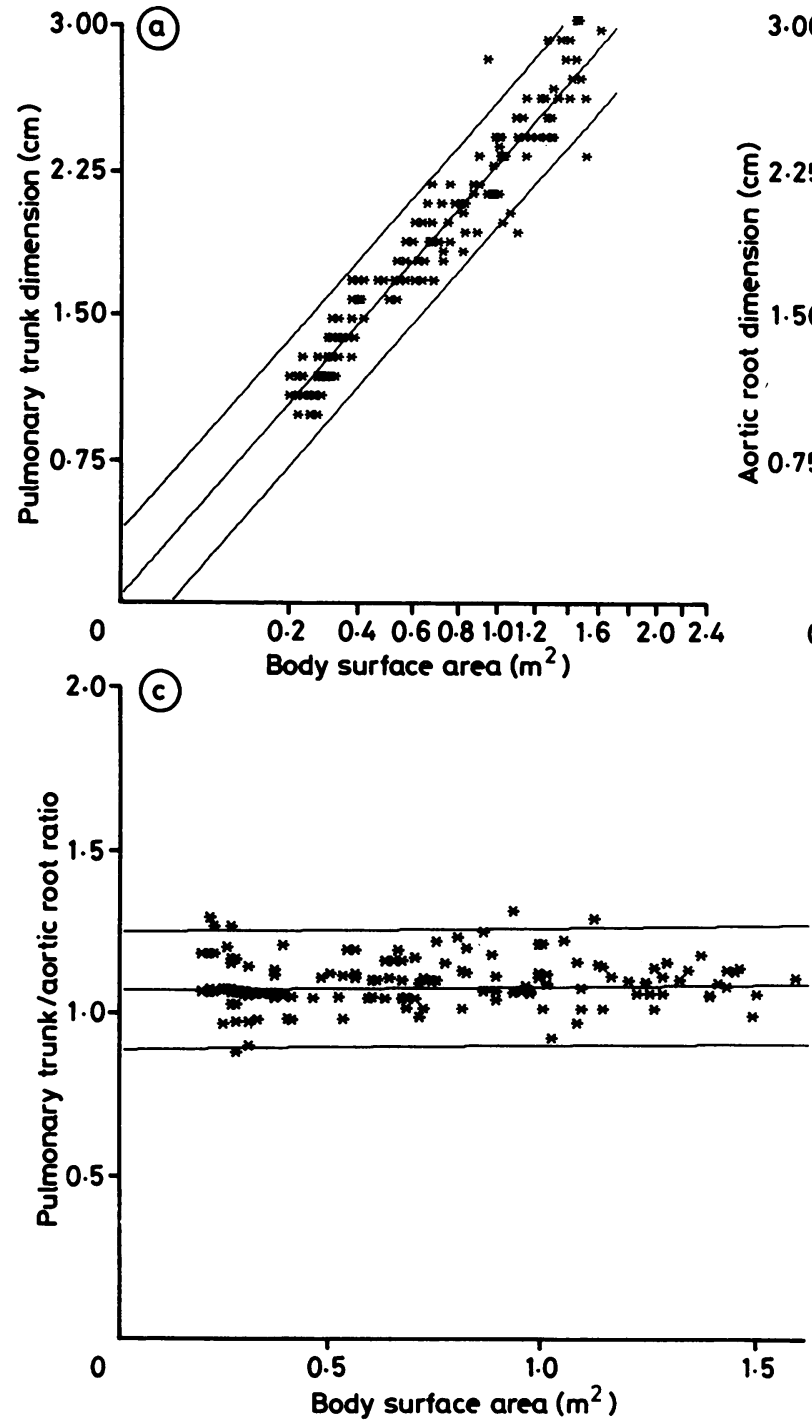

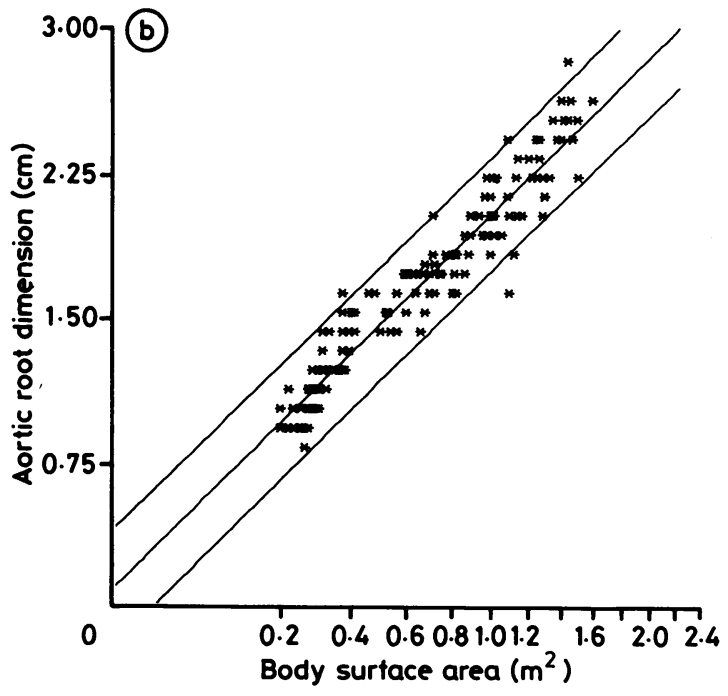

Fig 2 Echocardiographic diameters (in $\mathrm{cm}$ ) of the pulmonary trunk $(a)$ and the aortic root $(b)$ and (c) the pulmonary trunk to aortic root ratio plotted against body surface area $\left(\mathrm{m}^{2}\right)$ in 153 normal children aged 1 week to 15 years. infants and in group 2 as a whole (1.05(0.06)).

Eight of the 10 neonates in whom the echocardiographic diameters were obtained in the first 12 hours were restudied during the first week of life. The pulmonary trunk to aortic root ratio decreased considerably within one week after birth in all eight cases (fig 4).

Table 3 shows the differences between measurements of the great arteries obtained by different methods: in systole versus diastole, from the parasternal short axis view versus the long axis view, and the internal diameter of the pulmonary trunk versus the diameter obtained by the leading edge method.
The diameter of the pulmonary trunk and aortic root was slightly larger in systole than in diastole $(p<$ 0.001 ). The mean value of the pulmonary trunk increased by $4.3 \%$, the mean value of the aortic root by $3.4 \%$, while the pulmonary trunk:aortic root ratio remained unchanged. The pulmonary trunk in the parasternal short axis view was slightly smaller than in the long axis view $(p<0.001)$, whereas the aortic root in the parasternal short axis view was larger than in the long axis view ( $p<0.001)$. Consequently, the pulmonary trunk to aortic root ratio in the parasternal short axis view (0.99) was smaller $(p<0.001)$ than in the long axis view $(1.09)$. The 


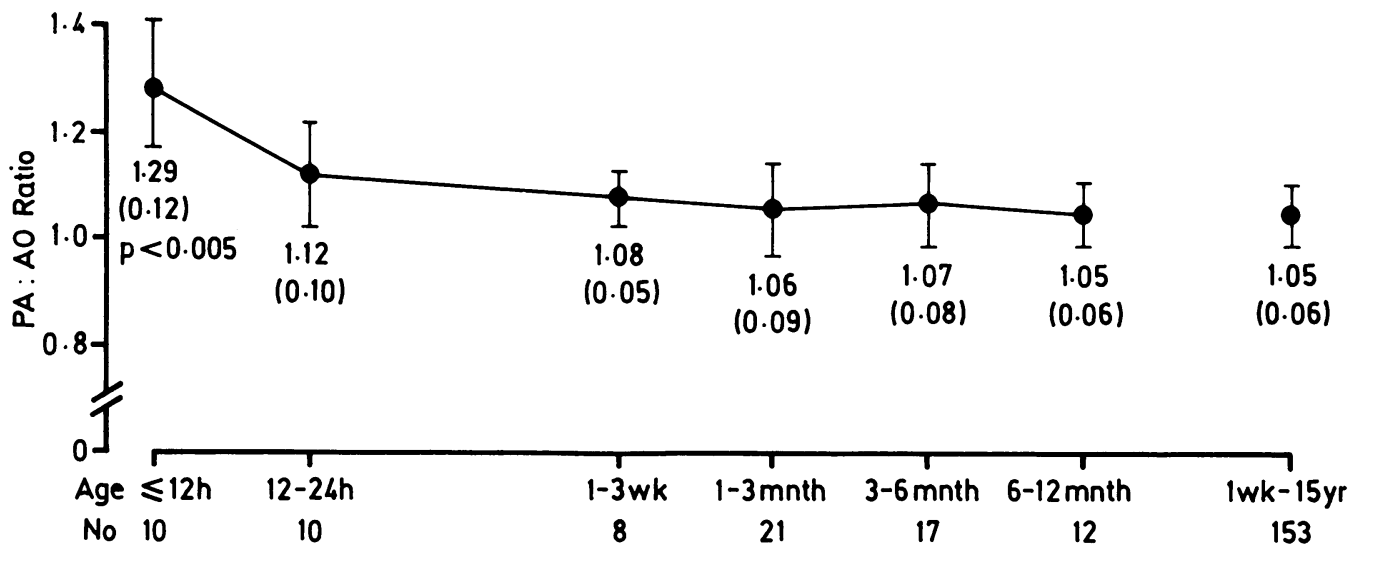

Fig 3 Pulmonary trunk to aortic root ratio (mean (SD)) in different age groups during the first year of life compared with the mean value for all 153 subjects in group 2 (aged one week to 15 years).

internal pulmonary trunk diameter (mean $1.55 \mathrm{~cm}$ ) and the pulmonary trunk to aortic root ratio $(1.05)$ derived from measurements of the internal diameter of the pulmonary trunk were slightly but significantly $(p<0.001)$ smaller than those obtained by the leading edge method (mean $1.62 \mathrm{~cm}$ for pulmonary trunk diameter and 1.09 for pulmonary trunk to aortic root ratio).

\section{Discussion}

In contrast with the large number of $M$ mode echocardiographic studies on aortic root dimension in normal children ${ }^{12-16}$ there are only a few reports of pulmonary trunk size. ${ }^{1517}$ Simultaneous visualisation of both pulmonary arterial walls on $M$ mode echocardiograms was difficult and measurements of the vessel diameter were unreliable ${ }^{13}$ or gave widely

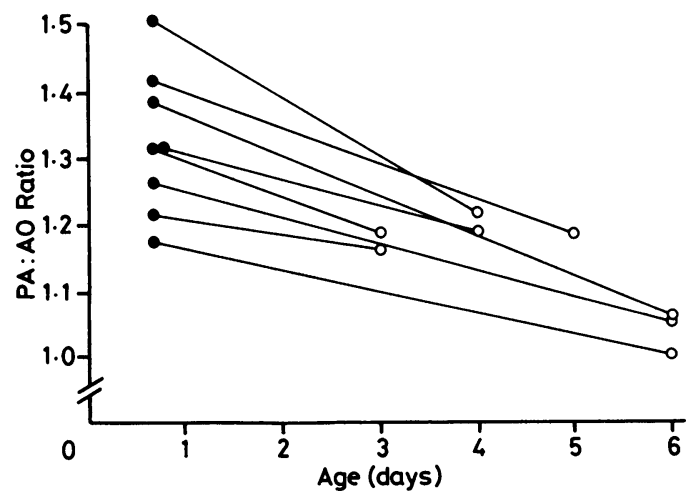

Fig 4 Sequential measurements of pulmonary trunk to aortic root ratio in eight neonates during the first week of life. scattered values. ${ }^{15}$ Cross sectional echocardiographic data on pulmonary trunk size are equally scant. Sahn et al obtained normal values for cardiac and great vessel dimensions in the fetus and immediately after birth. ${ }^{18}$ Aortic root and pulmonary trunk dimensions were reported by Snider et al in 110 normal subjects from the neonatal period to adulthood. ${ }^{6}$ The usefulness of their data is limited by the choice of the echocardiographic sections: for simultaneous visualisation of both great arteries the investigators selected the parasternal short axis view which, according to their own experience, causes considerable underestimation of the pulmonary artery size. This was confirmed in our study. We found it more difficult and time consuming to obtain a satisfactory image of the wall of the pulmonary trunk in the parasternal short axis view than in the parasternal long axis view and we also tended to underestimate the pulmonary trunk size in the short axis view, although the difference was less pronounced than that observed by Snider et al. ${ }^{6}$

Our results indicate that, with the exception of the first weeks of life, the dimensions of both great arteries show a linear correlation with the square root of the body surface area. This function also gave the best fit in an earlier cross sectional echocardiographic study. ${ }^{6}$ In $\mathrm{M}$ mode studies the size of the aortic root varied linearly with body surface area ${ }^{131516}$ or in relation to the cubic root of the body surface area. ${ }^{14}$ The graphic representation (fig 2) of the dimensions of great artery over a large range of body surface area should be useful in identifying abnormalities, particularly defects causing a left to right shunt, ${ }^{5}$ tetralogy of Fallot $^{8}$ or coarctation of the aorta. ${ }^{19}$

The pulmonary trunk to aortic root ratio was remarkably constant (mean 1.05(0.06)) in infants 
Table 3 Influence of method of measurement on dimensions of great arteries in infants and children $(n=173)$

\begin{tabular}{|c|c|c|c|c|}
\hline Variable & Dimension & Mean value of measurement $(\mathrm{cm})$ & Difference of the means & p value \\
\hline Phase of cardiac cycle & $\begin{array}{l}\text { PA LAX) } \\
\text { Ao(LAX) } \\
\text { PA:Ao(LAX) }\end{array}$ & $\begin{array}{cc} & \text { Diastole versus systole } \\
1.62 & 1.69 \\
1.49 & 1.54 \\
1.09 & 1.10\end{array}$ & $\begin{array}{l}0.07 \\
0.05 \\
0.01\end{array}$ & $\begin{array}{l}<0.001 \\
<0.001 \\
\text { NS }\end{array}$ \\
\hline Echocardiographic plane & $\begin{array}{l}\text { PA } \\
\text { Ao } \\
\text { PA:Ao }\end{array}$ & $\begin{array}{cc} & \text { Short axis versus long axis } \\
1.54 & 1.62 \\
1.56 & 1.49 \\
0.99 & 1.09\end{array}$ & $\begin{array}{l}0.08 \\
0.07 \\
0 \cdot 10\end{array}$ & $\begin{array}{l}<0.001 \\
<0.001 \\
<0.001\end{array}$ \\
\hline Measuring technique & PA(LAX) & $\begin{array}{l}\text { Internal diameter versus leading edge } \\
1.55\end{array}$ & 0.06 & $<0.001$ \\
\hline
\end{tabular}

See footnote to table 1 for abbreviations.

aged more than one month and throughout childhood; this gave a nearly straight horizontal regression line and a narrow confidence interval for the relation between pulmonary trunk to aortic root ratio and body surface area (fig 2 ). The finding that the pulmonary trunk is slightly larger than the aortic root confirms the results of previous studies on smaller numbers of normal children, in which the same echocardiographic view (parasternal long axis) and measuring sites were selected. ${ }^{57}$ Our results do not accord with those of Snider et al who found a wide scatter of pulmonary trunk to aortic root ratios and a pulmonary trunk dimension smaller than the aortic root dimension in most children. ${ }^{6}$ This difference may be partly explained by their use of the parasternal short axis view which, as shown in our study, leads to underestimation of the pulmonary trunk dimension and overestimation of the aortic root dimension.

We did not attempt to validate our results against invasive techniques or postmortem measurements. Our data, however, generally accord with such studies. Sievers et al reported on the angiocardiographic dimensions of the great arteries in 24 normal children. ${ }^{4}$ The mean values of pulmonary trunk dimension (at the pulmonary valve level) and aortic root dimension (just distal to the sinuses of Valsalva) give a pulmonary trunk to aortic root ratio of 1.06 in systole and 1.07 in diastole. In a pathological study De la Cruz et al reported that the ratio of the square of the orifice of the pulmonary artery to the aortic root was $1 \cdot 16,{ }^{1}$ which is slightly larger than the ratio of the great vessel diameters that we obtained. The considerable change in the dimensions of the great arteries that we found in the first days of life have not been reported before. Sahn et al reported normal data on great vessel diameters ${ }^{18}$ but this study was limited to the cardiac anatomy of the fetus in the second half of pregnancy and the neonate in the first 36 hours after birth. In their study, which included neonates, Snider et al related great vessel diameters solely to body surface area and not to age, ${ }^{6}$ which $\stackrel{\overbrace{}}{\mathcal{N}}$ makes it impossible to detect very early age-related 을 changes. As expected the pulmonary trunk diameter was found to be relatively large at birth. Sur- $\square$ prisingly, however, this dimension decreased rapidly. The largest diameters were noted in neonates who were $<12$ hours old. Significantly smaller diameters were found in those aged 12-24 hours and 3 days -3 weeks. In the 3-6 month age group the mean pulmonary trunk diameter was again equal to the measurement at birth and from three months on there was a steady increase in pulmonary trunk size that was related to body surface area and age. By contrast, the aortic root dimension increased gradually from birth onwards. Consequently the pulmonary trunk to aortic root ratio was greatest during the first hours of life but by one week had decreased rapidly to reach the "normal" value obtained in older infants and children. This change was distinctly shown in a subgroup of eight neonates in whom echocardiographic examinations were performed within 12 hours after birth and repeated in the course of the first week of life. Obviously, postnatal physiological changes of the circulation profoundly affect the size of the great arteries. The rapid decrease in the size of the pulmonary trunk coincides with the dramatic decrease in pulmonary vascular resistance and pressure and the redistribution of blood flow after birth, as extensively shown in fetal lambs. ${ }^{20}$.

The dimensions of the great arteries varied depending on the measuring technique. We systematically used the leading edge method which has been shown to be the most accurate. ${ }^{21}$ In some children, however, this method was found to be unreliable when used to measure the pulmonary trunk diameter from the parasternal short axis view. In this view the anterior edge of the pulmonary artery tends to be blurred. In these subjects only the inner diameter could be assessed. In an attempt to evaluate the effect of the measuring technique on 
vessel diameter we used both methods (leading edge to leading edge and inner to inner surface) to measure the pulmonary trunk in the parasternal long axis view. The internal diameter measurement gave slightly smaller values than the leading edge method. The fact that the difference was very small (mean $0.06 \mathrm{~cm}$ ) and negligible for clinical purposes may be because of our echocardiographic technique. We used a high resolution system and a minimum gain to obtain clear and thin echo lines and this somewhat reduced the wall thickness of the vessel.

When it is imaged in the parasternal plane, and particularly from the short axis view, the pulmonary trunk appears to change size with the cardiac cycle. We therefore measured the diameters of the great arteries in systole and diastole. Previous studies have shown that the cross sectional area of the aorta increases $5 \%-10 \%$ during systole while that of the pulmonary artery increases $2 \%$ to $18 \% \cdot{ }^{22}{ }^{23}$ Similar changes in diameter were seen in our study when the great artery dimensions were measured in the parasternal long axis view. The mean end systolic aortic root diameter was 3.4\% larger than the end diastolic diameter, while the pulmonary trunk diameter increased by $4.3 \%$. As these changes occurred simultaneously the pulmonary trunk to aortic root ratio was not influenced by the cardiac cycle. In the parasternal short axis view no consistent pattern in the systolic-diastolic changes was found. In most patients the diameter of the pulmonary trunk increased in systole, but in some it decreased. This decrease has also been reported by others when they measured the pulmonary trunk in the parasternal short axis view and has been attributed to a systolic movement of the pulmonary artery in such a way that the examining plane no longer passes through the centre of the vessel. ${ }^{24}$ Our results indicate that this factor has no major influence in the parasternal long axis view in which we found a small but consistent systolic increase in the size of the pulmonary trunk.

Our study provides normal values for cross sectional echocardiographic measurements of the pulmonary trunk and aortic root in neonates, infants, and children. We found that the parasternal long axis view was more reliable than the short axis view for measuring the pulmonary trunk. In contrast with the fairly wide $95 \%$ confidence intervals for pulmonary trunk and aortic root size, the pulmonary trunk to aortic root ratio showed little individual variability and was remarkably constant throughout infancy and childhood. The graphs relating these measurements to age (in neonates) or body surface area (in children older than one week) should be useful in assessing patients with congenital heart disease, particularly those with a decrease or increase in pulmonary blood flow.

\section{References}

1 De La Cruz MW, Anselmi G, Romero A, Monroy G. A qualitative and quantitative study of the ventricles and great arteries of normal children. Am Heart $J$ 1960;60:675-90.

2 van Meurs-van Woezik H, Klein HW, Krediet P. Normal internal calibres of ostia of great arteries and of aortic isthmus in infants and children. Br Heart $J$ 1977;39:860-5.

3 Jarmakani JM, Graham TP, Benson DW, Canent RV, Greenfield JC. In vivo pressure-radius relationships of the pulmonary artery in children with congenital heart disease. Circulation 1971;43:585-92.

4 Sievers HH, Onnasch DG, Lange PE, Bernhard A, Heintzen P. Dimensions of the great arteries, semilunar valve roots and right ventricular outflow tract during growth. Normative angiocardiographic data. Pediatr Cardiol 1983;4:189-96.

5 Gussenhoven WJ, van Leenen BF, Kuis W, de Villeneuve VH, Bom $\mathrm{N}$, van Meurs-van Woezik $\mathrm{H}$. Comparison of internal diameter of great arteries in congenital heart disease. A cross-sectional echocardiographic study. Br Heart J 1983;49:45-50.

6 Snider AR, Enderlein MA, Teitel DF, Juster RP. Two-dimensional echocardiographic determination of aortic and pulmonary artery sizes from infancy to adulthood in normal subjects. $\mathrm{Am} J$ Cardiol 1984;53:218-24.

7 Denef B, Dumoulin M, Van der Hauwaert LG. Usefulness of echocardiographic assessment of right ventricular and pulmonary trunk size for estimating magnitude of left-to-right shunt in children with atrial septal defect. Am J Cardiol 1985;55:1571-5.

8 Lappen RS, Riggs TW, Lapin GD, Paul MH, Muster AJ. Two-dimensional echocardiographic measurement of right pulmonary artery diameter in infants and children. $\mathrm{J} \mathrm{Am}$ Coll Cardiol 1983;2:120-6.

9 Boothby W, Sandiford RB. Normographic charts for the calculation of the metabolic rate by the gasometer method. Boston Med Surg J 1921;185:337.

10 Aubert AE. LILLY. A linear least squares curves fitting program. Handshake 1985;9:25-32.

11 Daniel C, Wood FS. Fitting equations to date. New York: J Wiley and Sons, 1980:10-3.

12 Lundström NR. Clinical applications of echocardiography in infants and children. Acta Paediatr Scand 1974;suppl 243:5-38.

13 Epstein M, Goldberg SJ, Allen HD, Konecke L, Wood J. Great vessel, cardiac chamber and wall growth patterns in normal children. Circulation 1975;51: 1124-9.

14 Henry WL, Ware J, Gardin JM, Hepner SI, McKay J, Weiner M. Echocardiographic measurements in normal subjects. Growth-related changes that occur between infancy and early adulthood. Circulation 1978;57:278-85.

15 Rogé CL, Silverman NH, Hart PA, Ray RM. Cardiac structure growth pattern determined by echocardiography. Circulation 1978;57:285-90.

16 Oberhänsli I, Brandon G, Friedli B. Echocardiographic growth patterns of intracardiac dimen- 
sions and determination of function indices during the first year of life. Helv Paediatr Acta 1981;36: 325-40.

17 Hagan AD, Deely WJ, Sahn D, Friedman WF. Echocardiographic criteria for normal newborn infants. Circulation 1973;48:1221-6.

18 Sahn DJ, Lange LW, Allen HD, et al. Quantitative real-time cross sectional echocardiography in the developing normal human fetus and newborns. Circulation 1980;62:588-97.

19 Morrow WR, Huhta JC, Murphy DJ, McNamara DG. Quantitative morphology of the aortic arch in neonatal coarctation. J Am Coll Cardiol 1986;8:616-20.
20 Rudolph AM. Congenital diseases of the heart. Chicago: Yearbook Medical Publishers, 1974: 17-48.

21 Feigenbaum HF. Echocardiography. 3rd ed. Philadelphia: Lea and Febiger, 1981:110-4.

22 Greenfield JC, Patel DJ. Relation between pressure and diameter in the ascending aorta of man. Circ Res 1962;10:778-81.

23 Greenfield JC, Griggs DM. Relation between pressure and diameter in main pulmonary artery in man. $J$ Apply Physiol 1963;18:557-9.

24 Goldberg SJ, Allen HD, Marx GR, Flinn CJ. Doppler echocardiography. Philadelphia: Lea and Febiger, 1985:80-6. 